\title{
THE IMPACT OF SCIENTIFIC AND TECHNICAL CHANGE ON THE LOCATION OF ECONOMIC ACTIVITIES
}

\author{
Martir J. BECKMANN * \\ and \\ Gunter SCHRAMM **
}

Received November 1971

\begin{abstract}
Summary: The impact of scientific and technical change on location and on the spatial structure generally poses a number of challenging theoretical problems and raises some momentous policy proble ts, because technical change is one of the main engines of economic growth, and rapid technical change and persistent economic growth are characteristics of our times. It is the purpose of this paper to analyze some of the theoretical implications of technological changte on th: location of economic activities to compare the findings with actual developments.
\end{abstract}

\section{Introduction}

Despite some claims to the contrary ${ }^{1}$ there is impressive evidence that a substantial percentage of the observed growth in real income per capita has been the result of technological change. ${ }^{2}$ Capital deepening has been the other most significant net contributor. ${ }^{3}$ However, much of the technological change is brought about and made effective by having new advances incorporated in the steady investment stream of new and replacement capital stock. Hence, it could be argued that almost all the increase in real income is a consequence of, or is at least dependent upon, technological change. Following this line of argument we could claim perhaps that observed changes in regional per capita incomes also reflect at least in part the underlying effects of changes in science and technology. ${ }^{4}$ In the majority of the industrialized western

* Brown Universicy, Providence, and Technische :Hochschule, München.

** University of Michigan, Ann Arbor. 
nations regional income disparities have been reduced in recent decades. ${ }^{5}$ Furthermore, for the world as a whole there is a striking inverse relationship between the degree of economic development and the degree of regional income inequalities existing in individual countries. Hence, we might want to claim that technological progress really contributes to an equalization of income opportunities, either by allowing lagging regions to become more efficient relative to the rest of the economy, or by increasing factor mobility which gradually removes the less efficient productive units to areas where their marginal productivity is higher. Unfortunately, in the case of at least one technologically advanced country, namely, Canada the evidence is not conclusive since its index of regional inequality has remained practically constant between 1926 and $1960 .^{6}$ This suggests that there is no real short-cut statistical answer to the underlying question of the effects of technological change on the relative growth rates of regional per capita income. What we will have to look for instead is an estimate of the effects of past and expected future technological changes on overall production functions for various types of industries and economic activities. Similar projections will hav' to be made for transportation costs of specific raw materials, semi-finished and finished products. Anyone who has attempted to make such estimates will quickly realize how formidable a task this is. ${ }^{7}$ Of necessity, therefore, the following discussion can provide no more than broad indicators of some of the important underlying technological forces that are affecting the overall trend of locational decisions.

\section{Agriculture}

Technical change in agriculture has lessened production cost at the farm and techrical improvements in transportation have lowered delivered prices for the consumer. In a Von Thünen diagram, as shown in fig. 1 , consider price of a given agricultural commodity as a function of distance from the city. Assume that demand for this product is perfectly inelastic. The required supply region is then given by the city's population and by the state of technology which determines the amount of land needed to satisfy per capita consumption. To the most distant farm, which represents the marginal producer, price received under perfect competition must just equal marginal production cost $c$. Price at the city equals $c$ plus transportation cost over the required distance $R$. 


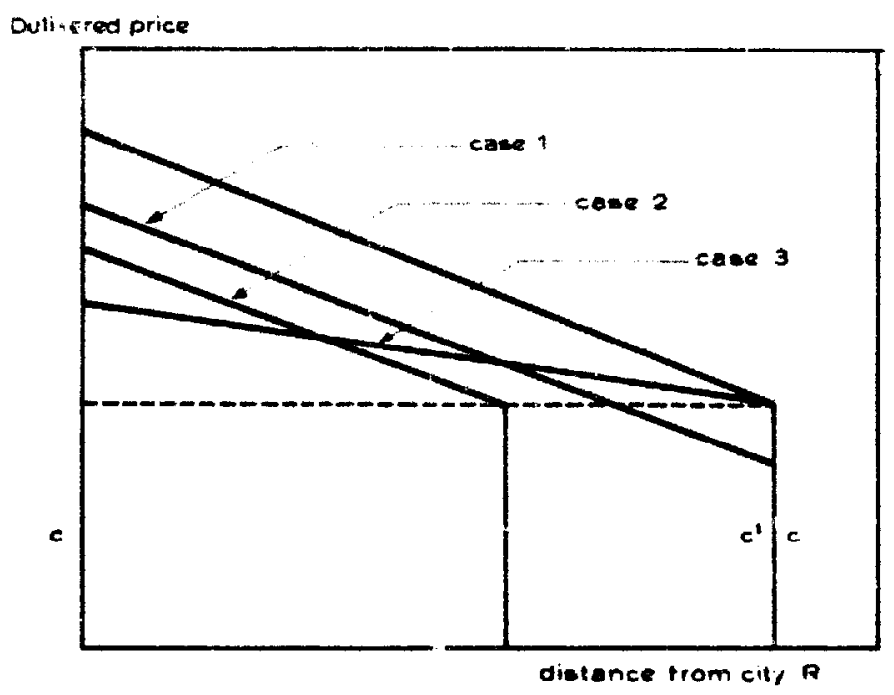

Fig. 1. Eftect of technological change on agriculture

$$
p=c+k R \text {. }
$$

Three effects may be distinguished. First, consider increased labor productivity and constant land productivity. Either the number of firms will decrease due to the indivisibility of a farmer's family or the number of farm laborers employed will fall $c$ will decrease to $c^{\prime}$ and the price line will shift parallel to itself in a downward direction. The supply area does not change. The total effect is a decrease of employment in agriculture and a reduction of agricultural prices. Second, consider increased productivity of land and constant productivity of labor. The required area of supply and hence the maximal distance both fall and this results in a parallel shift of the price line to the left by the amount of maximal distance saved. Third, a fall in transportation cost means that the price line is turned counterclockwise around its distant pivot. Notice that every one of these changes results in cheaper prices in the city and in the second and third cases in lower rents of land.

If the demand for farm products is not perfectly inelastic, then in case 1 the cultivated area will be extended, although the number of farms will rise only when demand is very elastic, an unlikely assumption for agricultural products. In case 2 the total supply area will still decline but by less than in the totally inelastic case. In case 3 the supply area will expand as in case $2{ }^{8}$ The general effects in all three cases are somewhat reduced but never reversed with elastic demand.

While this simple model can explain many of the changes that have taken place in our agricultural sector as a result of technological change 
it does not explain all of them. What has happened historically is that both labor productivity and land productivity heve increased greatly, the frrst through better education and capital augmentation (i.e. the addition of more efficient farm machinery) the second through improved seeds and the addition of fertilizers and insecticides. Four factors are of particular significance. First, the unit costs of net agricultural output in terms of capital-labor cost per unit of output have declined by more than fifty percent since the beginning of this century, or at about the same rate as the capital-labor costs per unit of output of the economy as a whole. ${ }^{9}$ Given the relatively inelastic demand for agricultural products, this means that the importance of agriculture relative to other sectors of the economy had to fall. As a consequence, the relative magnitude of the agricultural population to total population had to Jecline. Second, labor input per unit of output has fallen much more rapidly for agriculture than for GNP as a whole. ${ }^{10}$ This explains the rapid absolute decline in the agricultural hinterland population. Third, the technological improvements in agriculture have had a rather uneven effect on different agricultural regions. It proved to be much more beneficial to areas which were able to utilize large-sized machinery and uniform production techniques. Economies of scale, as well as technolof ical externalities have favored the iarge western and southern farming areas with their open, fertile lands at the expense of the small-scale, hilly and mountainous farming areas in the northeast. The latter were largely unable to take advantage of the economies of scale offered by the new large-size farm machinery and equipment. They also did not reap to the same extent as their western competitors the external benefits of large-scale storage, processing and marketing facilities since good agricultural land in the northeast is more scattered. Fourth, the relative importance of transportation costs to total costs has substantially declined as a consequence of technological improvements. This has made it possible for the more efficient western farmers to penetrate the local markets of the higher-cost northeastern producers. As a consequenci, the relative incomes of the latter have declined to such an extent that most of the less efficient producing units are no longer economically viable. Technological change, therefore, is largely responsible for the decline in the fortunes of eastern agriculture. While it should be possible to ameliorate this decline somewhat by creating larger productive farming units, the disadvantages of poorer soils, topography and climate will permanently prevent a return of northeastern agriculture to the relative importance as a food producer for this co itinent which it had held in earlier decades. 


\section{Impact on a given location}

The folklore of development economics, that economic change benefits everybody, is easily exposed as a theoretical fallacy. Technical change may render some skills obsolete while putting a premium on others. In the same way natural resources and their locations may reap windfalls or suffer as technical change changes the need for material inputs. It might seem that in view of this almost nothing can be said in a general way about the impact of technical change on particular localities. This is true for resource deposits. However, the case is different with locations that are trading centers, i.e., central places. While it is unlikely that technical change alone will ever elevete some outlying place in the Northwest territories to the rank of a high order center it is equally unlikely that the metropolitan centers of today will ever lose their function as high order central places. However, it is a different matter whether they will keep their present size, will grow relatively or absolutely, or decline. It is not difficult to see that the structural proportions in a ceńtral place hierarchy are dependent on technological facts. If the latter change, something can be said about foreseeable changes in hierarchical proportions.

The question to be analyzed specifically here is: how does technical change affect the distribution of population as between centers and cities of various size? This problem will be studied in the framework of a central place hierarchy. In a recent publication the follo wing structural relationships were found to hold: ${ }^{11}$

The size of a city of given rank is proportional to the basic rural population served by the city of lowest rank times a coefficient which is a function of the multipliers for activities carried out in cities up to the given rank and of the numbers of satellites at this and lower levels of the hierarchy. A mathematic analysis of this central place model shows the following: 12

Any labor saving technical change will decrease the man hours $k_{i}$ required for services $i$ to one person and hence would tend to lower the city hinterland ratio at all levels of the hierarchy. This, however, is only one possible direct effect. The indirect effects of such technical change include increases in per capita income and in the demand for services. Thus, in effect the amount of service rendered per capita has grown and so have the $k_{i}$ resulting in increasing urbanization of population. 
Every increase in a service coefficient $k_{i}$ tends to raise the population difference at each step between cities of higher order than $i$. The impact of an increase in one $k_{i}$ is thus cumulative and larger the higher the level. Here we have in a nutshell the effect that technical change tends to multiply city size by a multiplier which grows with the city's rank. This conclusion is supported by empirical facts. Both in the United States and in Canada the highest growth rates occurred in metropolitan areas while smaller, isolated towns lagged far behind and rural areas remained almost stagnant. ${ }^{13}$

One important impact of technical change in the distribution services has been to virtually eliminate the economic viability of centers of lowest order. This is due partly to the supermarket as a more effective distribution device and partly to the automobile, which increases access to higher order centers with their larger variety of choice. The auto has tnus serred to increase demand for higher order services and has raised the respective $k_{i}$. The impact of technical change on the central place structure can be summarized under the catchword: urbanization. It has resulted in a decrease in the rural population and the shrinkage of the lower order centers serving these and in a relative and absolute increase in the size of centers at tile top of the hierarchy. Recent empirical studies have come to the same conclusion. As the U.S. Advisory Commission on Intergovernmental Relations points out: ${ }^{14}$

The minimum size 'independent' community (i.e. located well outside a metropolitan area) that can provide empleyment opportunities is growing, due to technological and economic factors. Twenty five thousand to 50000 appears to be the ninimum viable population. Smaller towns away from metropolitan areas thus will have difficulty in surviving as employment centers except for certain limited purposes.

These findings hold important lessons for our governmental efforts to bring about a readjustment of regional income distribution. It might be either futile or overly costly to try to stem the decline of many of our smaller, more isolated communities whose economic fortunes have declined with the shrinking importance of an agricultural hinterland or with the exhaustion of some extractive natural resources base. Instead, a positive policy of resettlement in viable grow th centers ${ }^{15}$ which serve as the transportation and service hub for a wider area might be much more sensible. 
4. Some aspects of the effect of increasing urbanization on industrial plant orientation

In the classical Weber model, and no treatise of this kind would be complete without one, forces of supply and of demand pull in the direction of their respective locations with forces proportional to the weights that have to be moved. As population becomes more concentrated the forces of demand which were dispersed tend to pull in one or a few directions, those of large population centers. This at any rate applies to consumer goods industries, but as these become oriented to consumption centers it applies in turn to their suppliers, to the suppliers of these suppliers, etc. Thus it is that resource orientation tends to give way to market orientation. In the case of the processing industries which convert a single material input into a single material output with the use of labor, capital services and ubiquitous resources, technical change tends to reduce input weights (less coal and iron ore go into steel as a result of the oxygen process). At the same time, innovations that change the product often go in the direction of more bulk, more weight, higher value and in many cases lesser transportability. That the opposite occurs should not be forgotten. Ravios and some cars are more compact today. Plastics and improved design have contributed to lesser weight and/or bulk of some finished goods. Thus transportation costs of inputs or outputs can exert a significant influence on the location of industrial plants. When inputs are heavy, bulky or contain large quantities of waste materials transportation costs will usually make a plant location near the place of origin of these inputs more attractive than other alternative locations. However, if inputs are ubiquitous or come from many different sources and locations and if the costs of transportation of the plant's products to markets are high relative to their value a market location might be more attractive. The increasing concentration of population in larger and larger urban centers gradually shifts the balance between an origin-of-inputs related losation to a point-of-destination location for many operations.

There are several additional forces at work that tend to accelerate this process. The first is that a majority of technological improvements in production are coupled with substantial economies to scale. This means that industries, in order to take full advantage of them, have to increase the size of their individual factories. Automobile assembly plants provide a good example. As George Romney once testified, scale economies are quite substantial up to an annual plant capacity of 


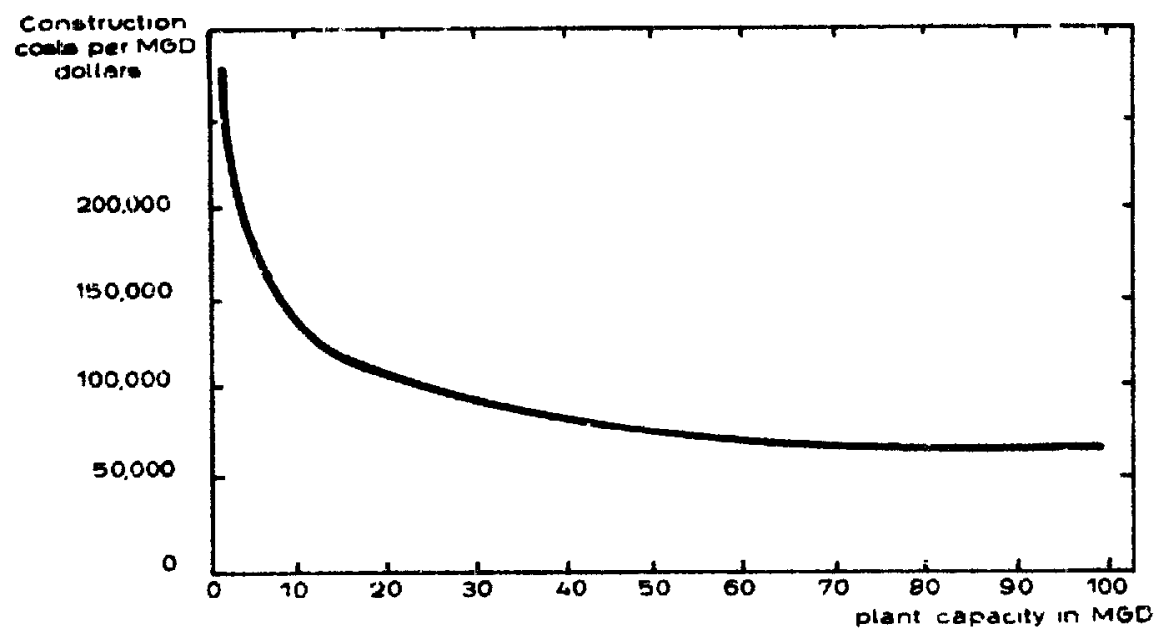

Fig. 2. Water purification plant construction costs per MGD capacity. Calculated from Eliassen (1967), p. 89. The data refer to the costs of coagulation-sand filtration plants.

360000 to 440000 units; ${ }^{16}$ further but rapidly decreasing additional cost advantages accrue to plants of up to about double that size. ${ }^{17}$ Increased individual plant sizes mean larger work forces, and larger work forces result in larger urban concentrations. Scale economies in industrial production processes, therefore, contribute directly and rather significantly to urban growth and urban concentrations.

Second, there are similar technologically determined scale economies available in the production and distribution of practically all of our basic utility services. Figs. 2 to 4 provide typical examples. Fig. 4 , for example, shows that average generating costs per $\mathrm{kW} / \mathrm{hr}$ from thermal power plants fall by some $37 \%$ when unit sizes are increased from 100000 to $600000 \mathrm{~kW}$ per unit in a two-unit plant. ${ }^{18}$ The water supply and sewage treat:nent plant cost functions display similar unit cost decreases as plant size increases. These potential, technologically determined cost savin ${ }_{b}$ bestow significant economic advantages on the larger urban centers or urban conglomerations. They are another contributing factor to the more rapid growth of the latter.

A third factor contributing to this trend is the fact that advances in transportation technology have not been evenly distributed over all types of transportation modes and tor all types of materials. Automation and the development of special handling equipment have led to relatively much greater cost reductions in the handling of uniformly sized, large volume merchandise. The containerized ocean-railroad traffic developing between high-volume points of shipping provides a 


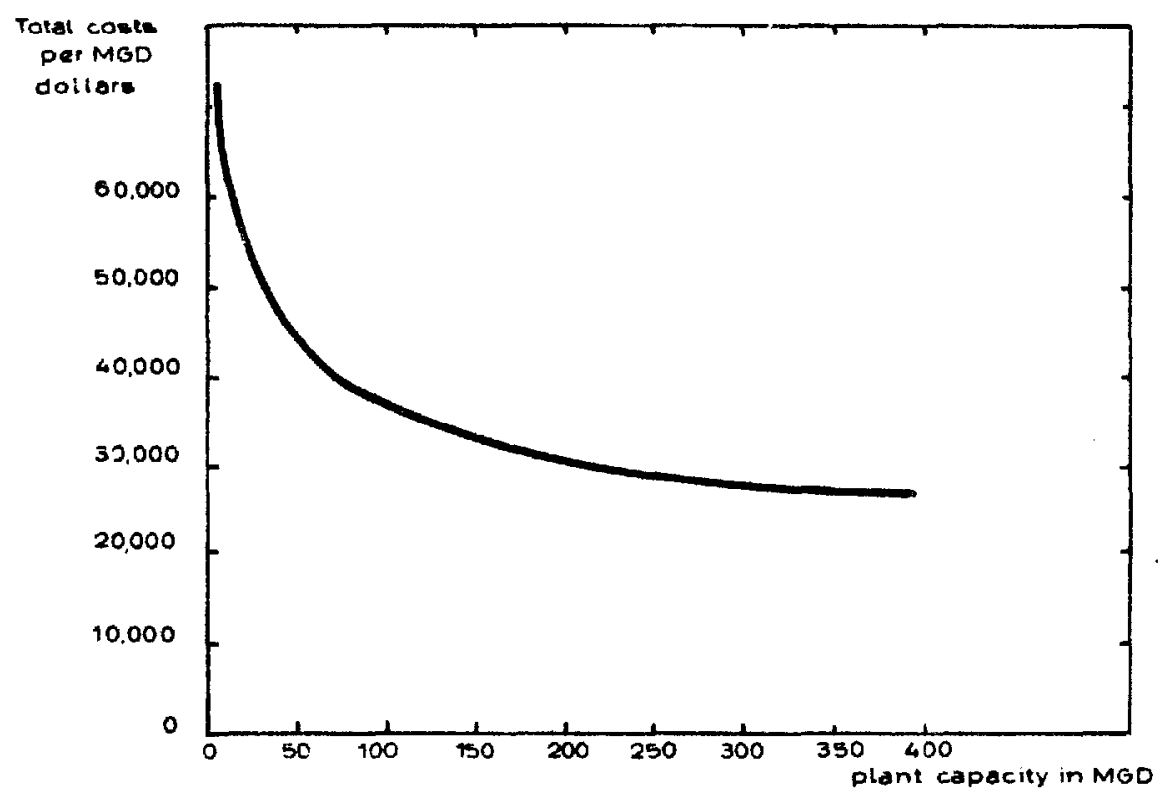

Fig. 3. Organic waste water treatment plant. Capital costs per MGD capacity. Calculated from Eliassen (1967). Data refer to the total capital costs of the operating building of an activated-sludge waste treatment plant.
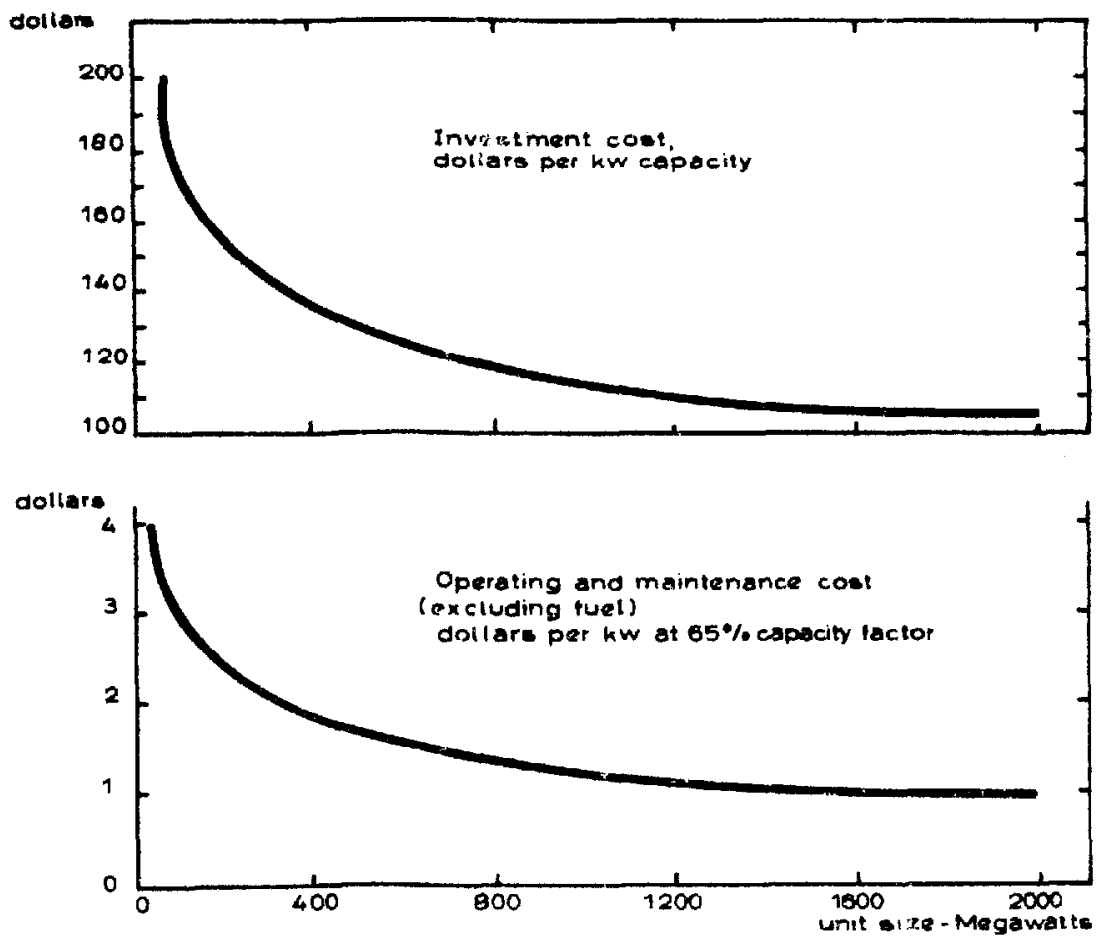

Fig. 4. Cost characteristics of coal-fired steam-electric power plants (two-unit). Reproduced from Federal Power Commission (1964), Part I, p. 70. 


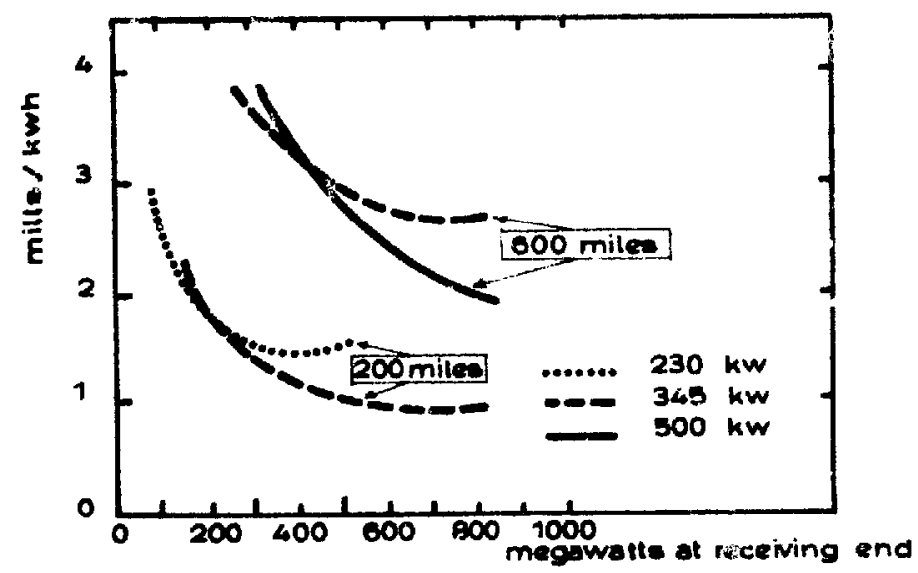

Fig. 5. Cost of slectrical transmission. Reproduced from Federal Power Commission (1964), Part I, p. 152.

good example. However, only large volume shipping and receiving areas can take advantage of these trends, a fact which again makes large-sized plants and large-volume points of production and destination more competitive. Similar cost advantages accrue to large volume shippers and receivers of other transportation modes. Figs. 5, 6 and 7 clearly indicate the economies of scale available in the transportation of electric energy, people and liquids. Finally, major technological advances have been made in the transportation of bulk materials. Their shipping costs, relative to the shipping costs of cargo have fallen drastically in recent years. For exarnple, it is generally less costly to move two tons of alumina in bulk carriers than its molten-down equivalent of about one ton of aluminium ingots over the same distance. ${ }^{19}$ However, in order to take advantage of the:e potential cost savings it is again necessary to move high volumes from points of origin to points of destination. ${ }^{20}$ These two factors combined have brought about an almost revolutionary change in the locational decisions of many industries. For example, the alumir am smelting industry, once almost totally oriented towards the location of cheap electric power sources now is almost exclusively market oriented. ${ }^{21}$ Technological changes in transportation costs, therefore, also are contributing towards the relative cost advantages of large urbanized centers of population.

While all of these factors tend to reduce the private costs of producing, doing business, and obtaining consumption goods in the larger urban centers, ${ }^{22}$ all of us are painfully aware that large urban concentrations appear to result in substantial additional social costs. High 


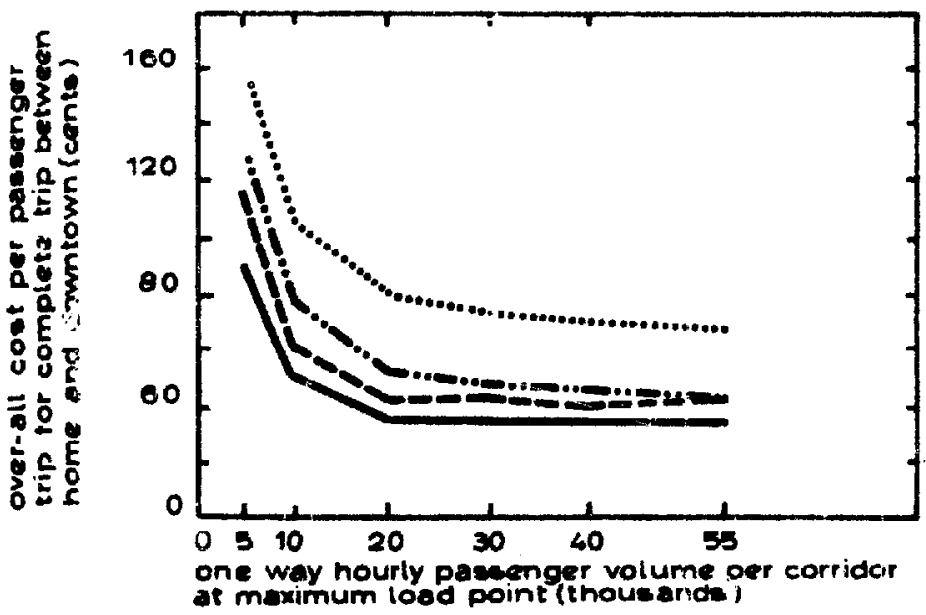

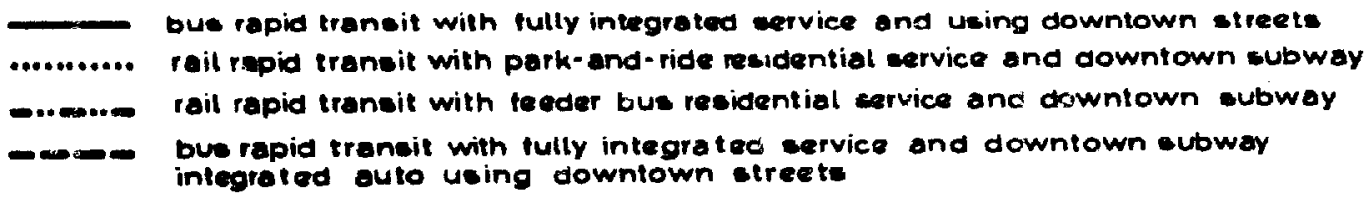

Fig. 6. Overall home-downtown passenger-trip costs for medium residential density city. Repruduced from Meyer et al. (1968), p. 213. The data refer to transportation costs along a special corridor, hourly downtown passenger trip origination of ten per block at the home end, 10-mile line-haul facility, and two-mile dov'ntown distribution system route length.

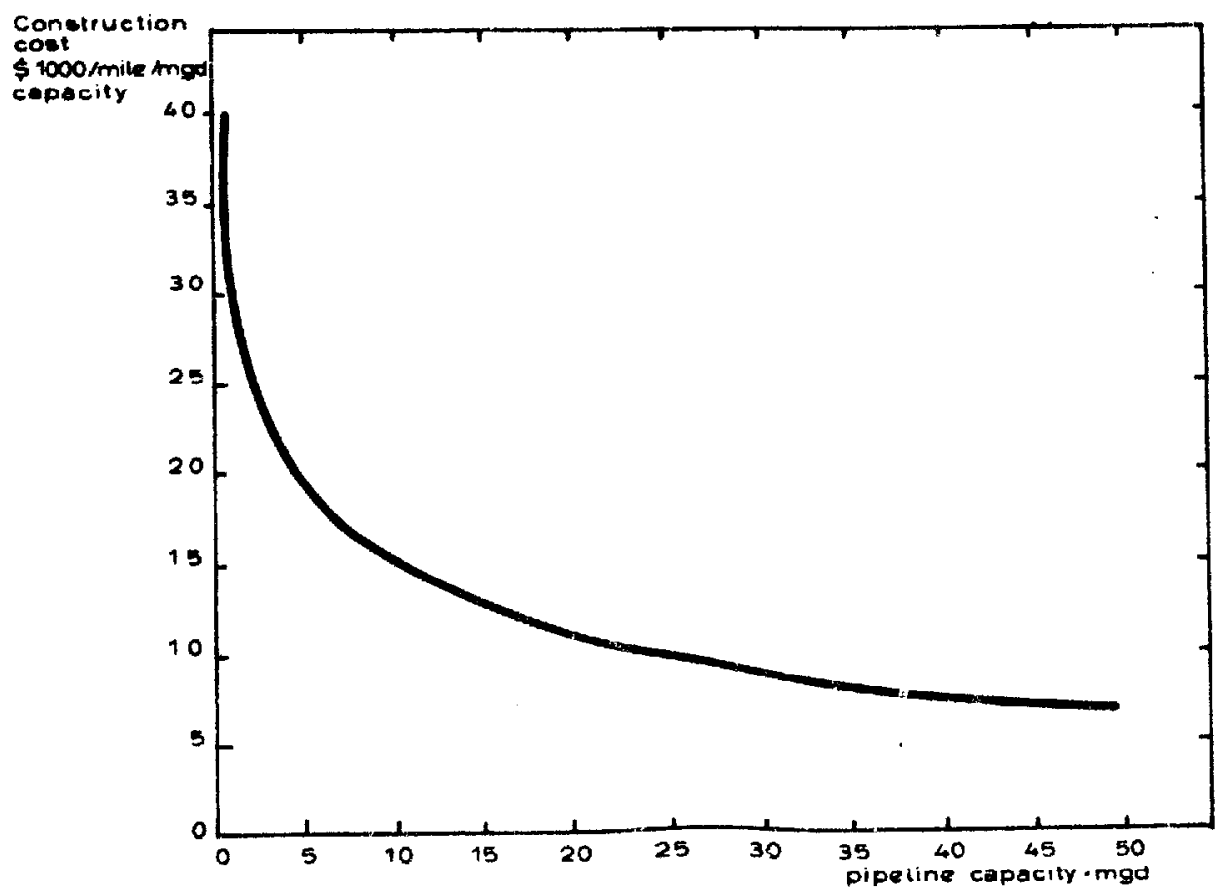

Fig. 7. Water transmission pipeline construction cost. Calculated from Eliassen (1967). p. 85. 
crime rates and concentrated air and water pollution are only a few examples of these costs. In addition, some observers have claimed that cities with large populations incur significantly higher municipal government expenditures per capita. ${ }^{23}$ However, while this is basically true, it does not prove at all that there are diseconomies of scale at work, as Gail Wilensky has recently shown (Wilensky, 1970). There is no doubt, however, that many private operating costs in larger urban centers will increase if sensible pricing policies are adopted with respect to air, water and land pollution problems. ${ }^{24}$ While this is a fascinating and important issue it is one which goes quite beyond the scope of this discussion.

\section{Appendix A}

The effects of technological change on city size in a central place hierarchy

The size of a city of level $n$ in the central place hierarchy is

$$
C_{n}=r\left[\frac{k_{1}}{1-k_{1}}+\frac{1}{1-k_{1}} \sum_{i=2}^{n} \frac{k_{\mathrm{i}}}{1-K_{i-1}} \prod_{j=1}^{i-1} \frac{\left(1+m_{j}\right)\left(1-K_{j}\right)}{1-K_{j+1}}\right]
$$

and the population served is

$$
P_{n}=\frac{r}{1-k_{1}} \prod_{i=1}^{n-1} \frac{\left(1+m_{i}\right)\left(1-K_{i}\right)}{1-K_{i+1}}
$$

Here $r$ denotes rural populations served by a city of lowest rank $n=1$, $k_{i}$ number of people in a city required to perform functions of level $i$ for one person, $K_{i}=\Sigma_{j=1}^{i} k_{j}$, and $m_{i}$ number of sateilites of a city of level $i+1$. Notice first that all cities are proportional ir: size to the basic rural populations served. If the rural base shrinks, so would the cities in exact proportion. (This is not strictly true if other base activitics such as mining are added. But the population employed in mining is by orders of magnitude smaller than that in agriculture.) The ratio of city to hinterland or city to total populations served is independent of $r$ and is, therefore, not affected by the thinning of the rural population. Taking the ratios of (1) and (2) 


$$
\frac{C_{n}}{P_{n}}=\sum_{i=1}^{n} \frac{k_{i}}{1-K_{i-1}} \prod_{j=1}^{n-1} \frac{1-K_{j+1}}{\left(1+m_{j}\right)\left(1-K_{j}\right)}
$$

Writing $\frac{k_{i}}{1-K_{i-1}}=1-\alpha_{i}$

$$
\frac{C_{n}}{P_{n}}=\sum_{i=1}^{n}\left(1-\alpha_{i}\right) \prod_{j=i+1}^{n} \frac{\alpha_{j}}{1+m_{j-1}} .
$$

Assume that all $m_{j}$ are equal and write $\mu=1+m$

$$
\frac{C_{n}}{P_{n}}=\frac{1}{\mu^{n}} \cdot \sum_{i=1}^{n}\left(1-\alpha_{i}\right) \mu^{i} \prod_{j=i+1}^{n} \alpha_{j}
$$

from which

$$
\frac{\mu_{n} C_{n}}{P_{n}}=\mu^{n}+\sum_{i=2}^{n-1} A_{i} \mu^{i}(1-\mu)-\mu A_{0}
$$

where $A_{i}=\prod_{j=i+1}^{n} \alpha_{j}$

Now $\quad \frac{\mathrm{d}\left(C_{n} / P_{n}\right)}{\mathrm{d} A_{i}}=\mu^{i}(1-\mu)<0 \quad 0<i<n$

$$
\frac{\mathrm{d}\left(C_{n} / P_{n}\right)}{\mathrm{d} A_{0}}=-\mu<0 \text {. }
$$

But

$$
\begin{aligned}
& \mathrm{d} A_{i} / \mathrm{d} \alpha_{j}>0 \quad j>i \\
& \frac{\mathrm{d} \alpha_{j}}{\mathrm{~d} k_{j}}=-\frac{1}{1-K_{j-1}}<0 .
\end{aligned}
$$


By the chain rule of differentiation thus

$$
\frac{\mathrm{d}\left(C_{n} / P_{n}\right)}{\mathrm{d} k_{j}}>0 \quad \text { for all } j \leq n
$$

In order to study the differential impact of technical change on cities ai various levels of the hierarchy we consider $\gamma_{n}=\left(C_{n}-C_{n-1}\right) / r$. On the assumption that the number of satellites is constant $m_{j}=m=$ $\mu-1$ one obtains from (1)

$$
\gamma_{n}=\frac{k_{n} \mu^{n-1}}{\left(1-K_{n}\right)\left(1-K_{n-1}\right)}
$$

Now

$$
\frac{\partial \gamma_{n}}{\partial k_{i}}= \begin{cases}0 & i>n \\ \mu^{n-1} /\left(1-K_{n}\right)^{2}>0 & i=n \\ \mu^{n-1} \frac{k_{n}\left(2-K_{n-1}-K_{n}\right)}{\left(1-K_{n}\right)^{2}\left(1-K_{n-1}\right)^{2}}>0 & i<n\end{cases}
$$

A change in the service coefficient $k_{i}$ affects only cities of rank $n \geq i$. The impact of a given change $\Delta k_{i}$ is an increasing function of city rank $n$. Also the impact of $k_{n}$ on $\gamma_{n}$ is larger than that of $k_{i}$ for $i<n$ provided empirical values are substituted for $k_{i}$. Orders of magnitude are $k_{1}=0.2$ $k_{i}=0.02, i>1$.

\section{Footnotes}

1 See D.W. Jorgenson and Z. Griliches (1967).

2 For the U.S., Solow has estimated this rate to be $1.6 \%$ p.a. for the period between 1900 and 1950. See R.M. Solow, 1957, Technical change and the aggregate production function, Review of Economics and Statistics. For Canada the estimated growth rates per employed persons are approximately $1.1 \%$ or about $2 / 3$ of the estinated total increase in real ourput. From: Economic Council of Canada, The Canadian Economy from the 1960's to the 1970's, Ottawa, Sept. 1967 , table 4-4. 
3 According to the Economic Council, capital deepening contributed the other 0.5 percent of real growth per employed person in the 1955-62 period, while the advances from better education were offset by reductions in hours worked and the changing age-sex composition of the labor force. Ibid.

4 Such an assumption, in order to be reasonably realistic, would have to ascribe a great many important factors that have influenced relative changes in regional incomes at least indirectly to technological change. One of them would be the substantial increase in factor mobility, for example.

5 See J.G. Williamson (1968), pp. 99-158.

6 Ibid, table 5.

7 See, for example, Sterling Brubaker (1966), particularly chs. 7, 9 and 10.

8 In terms of fig. 1 this means that the price line has to shift upward as it pivots around. However, the resulting increase in delivered prices at the city is of necessity lower than the overall decrease in prices resulting from the reduction in transportation costs.

9 Barnett and Morse have estimated a decline from an average of $132(1929=100)$ in the 1870-1900 period to 66 in 1957 for agriculture and from 136 to 68 for total GNP less extractive resources (U.S. data). This trend has continued since then. For example, bctween 1956/ 1958 and $1962 / 64$ the average U.S. yield per acre has risen by $10.3 \%$ for what, $30.7 \%$ for corn and 4.5\% for soybeans. Data from (a) Barnett and Morse (1963) p. 205 : (b) Committee on Resources and Man (1969), table 4.5.

10 The 1957 relative agriculture to GNP U.S. index has been estimated at 77 (1929-100). From Barnett and Morse (1963), p. 205.

11 Beckmann and McPherson (1970), pp. 25-33.

12 The mathematical analysis is contained in Appendix $A$.

13 In the U.S., the $1960 / 65$ population growth rate in metropolitan areas was $10.1 \%$, in nonmetropolitan urban places with a population of 10000 or more $6.0 \%$, and in all non-metropolitan areas combined only 3.9\%. From: Advisory Commission on Intergovernmental Relations (1968), p. 7.

In Canada, between 1951 and 1961 the population of 17 official Car ucian Census Metropolitan areas increased ly $45.1 \%$; those of all other towns and villages with a population of more than 1000 by $25.5 \%$ while the population outside these urban areas increased by only 1.7\%. Calculated from: Dominium Bureau of Statistics (1967), ch. II:, tables 4, 6 and 8. 14 Advisory Commission on Intergovernmental Relations, op. cit., p. 58.

15 Such is the systematic resettlement policy for Newfoundland's ou wort fishing villages.

16 This refers to a two-shift operation.

17 Donald S. Watson (1969), pp. 127-128.

18 For a more detailed discussion of the effects of scale economics on electric power costs see G. Schramm (1969).

10 As Brubaker has stated: "Steamship rates for ingot tend to be 2-3 times the rate for raw materials," (1967), p. 160).

20 For example, the use of specially dexigned, integral unit trains instead of ordinary shuttle trains for hauling coal from a mine to a large thermal power plant reduces costs per 100 miles from a range of 1.8 to $3.6 \mathrm{c} /$ million btu to one of 0.7 to $2.0 \mathrm{c}$ /million btu. From: Federal Power Commission, The 1970 National Power Survey, Part III, Washington, p. III-3-118. 21 In recent years major smelters have been built in Great Britain, Germany and Japan by the same firms that had located their plants previously in areas of cheap hydro power such as Canada and the U.S. Pacific Northwest.

22 In addition, large urban centers reduce the risk of failure or unemployment by offering more alternative opportunities.

23 It has been found, for example, that per capita costs of many public services increase in centers of population with more than 250000 people. See Advisory Commission on Intergovernmental Relations, op, cit. p. 56. 
24 l.e. pricing policies that vary charges for polluting activities according to the damages caused. This would bring about much higher pollution abatement costs in large urban centers where greater demands are made on the existing air and watershed. Since pollution abatement costs increase rapidly with higher standards this would increase production costs in large cities more than elsewhere. For a more detail dd discussion of the issues involved see, for ixample, Kneese and Bower (1968) and Dales (1968).

\section{References}

Advisory Commission on Intergovernmental Relations. 1968. Urban and Rural America: Policy for Future Growth, Washington, April.

Barnett. Harold J. and Chandler Morse, 1963. Scarcity and Growth (Johns Hopkins Press, Baltimore, Maryland).

Beckmann, Martin J. and John C. McPherson. 1970. City size distribution and central place hierarchy, an alternative approach, Journal of ?egional Science 1, 25-33.

Brubaker, Sterling. 1966. Trends in the World Aluminium Industry (Johns Hopkins Press, Baltimore, Maryland).

Committee on Resources and Man, National Academy of Sciences-National Research Council, 1969. Resources and Man (W.H. Freeman, San Francisco).

Dales, J.H. 1968. Pollution, Property and Prices (University of Toronto Press, Toronto).

Dominium Bureau of Statistics. 1967. Canada Yearbook 1967, Ottawa.

Economic Council of Canada. 1967. The Canadian Economy from the 1960's to the 1970's, Ottawa, September.

Eliassen, Rolf, 1967. The Economics of Water in the Pulp and Paper Industry, Department of Civil Engineering, Stanford University, Stanford, California, June.

Federal Power Commission, 1964. Nat onal Power Survey.

Federal Power Commission. 1970. The 1970 National Power Survey Washington.

Jergensen, D.W. and Z. Griliches. 1967. The explanation of productivity change, Review of Economic Studies.

Kneese, Allen V. and Blair T. Bower. 1968. Managing Water Quality: Economics, Technology, Institutions (Johns Hopkins Press, Baltimore, Maryland).

Meyer, J.R., J.F. Kain and M. Wohl. 1968. Urban transport costs. in: Transport, Denys Munby, (Penguin Books, Baltimore, Maryland).

Schramm, G. 1969. The effects of low-cost hydro power on industrial location, Canadian Journal of Economics III, 2, May.

Watson, Donald S. 1969. Price Theory in Action, 2nd ed. (Houghton-Miffin Company, Boston).

Wilensky, Gail R. 1970. Determinants of local government expenditures, in: Financing the Metropolis, J.P. Crecine (Sage Publications, Beverly Hills).

Williamson, J.G. 1968. Regional inequality and the process of national development: Adescription of patterns, Economic Levelopment and Cultural Change 13, as reprinted in: Regional Analysis, ed. L. Needleman (Penguin Books, Baltimore). 